\title{
Efficacy of Intra-Cystic Methotrexate Injection in Management of Benign Persistent Ovarian Cysts
}

\author{
Adel El Gergawy, Ahmed El Halwagy, Ayman S. Dawood*, Mohamed E. Kabeil \\ Department of Obstetrics and Gynecology, Faculty of Medicine, Tanta University, Tanta, Egypt \\ Email: ^ayman.dawood@med.tanta.edu.eg
}

How to cite this paper: El Gergawy, A., El Halwagy, A., Dawood, A.S. and Kabeil, M.E. (2017) Efficacy of Intra-Cystic Methotrexate Injection in Management of Benign Persistent Ovarian Cysts. Open Journal of Obstetrics and Gynecology, 7, 51-60. http://dx.doi.org/10.4236/ojog.2017.71006

Received: November 16, 2016 Accepted: December 27, 2016 Published: December 30, 2016

Copyright (c) 2017 by authors and Scientific Research Publishing Inc. This work is licensed under the Creative Commons Attribution International License (CC BY 4.0).

http://creativecommons.org/licenses/by/4.0/ c. (i) Open Access

\begin{abstract}
Aim: To evaluate and compare the efficacy of methotrexate injection in management of persistent simple ovarian cyst versus the use of transvaginal ultrasound aspiration alone. Patients and Methods: This randomized controlled study was conducted at Tanta University Hospitals in the period from April 1, 2016 to October 31, 2016. Patients were randomly allocated into two groups; each group has 25 patients with benign persistent simple ovarian cyst. Group I: Patients were subjected to transvaginal aspiration of the cyst. Group II: patients were subjected to methotrexate injection inside the cyst. Patients in both group were followed up at 1, 3, 6 months after procedure for the recurrence and occurrence spontaneous pregnancy. Results: The mean age in group I was 28.8 years, and the mean age in group II was 26.52 years with non-significant difference. Also there was non-significant difference between both groups regarding size of the cyst. No case recorded to have a cyst recurrence in group II and four cases in group I within six months with significant difference ( $P$ value 0.037$)$, and there was non-significant differences as regard the pregnancy rate and complications. Conclusion: Transvaginal intra-cystic methotrexate injection is a safe and effective choice for management of persistent simple benign ovarian cyst.
\end{abstract}

\section{Keywords}

Simple Cyst, Methotrexate, Ultrasound Guided, Aspiration, Recurrence

\section{Introduction}

Ovarian cysts are common findings in women throughout their lifetime. Ovarian cysts include three main types: functional, benign or malignant. Benign cysts are by far the most common in the great majority of cases. Benign cysts usually can be managed conservatively. Some ovarian cysts are symptomatic and may require surgical management. The incidence of cystic ovarian lesions ranges from $5 \%$ to $15 \%$ [1]. 
It had variable clinical manifestations, majority being discovered accidentally during ultrasound examination. Most cysts are safely left with no interference, and are monitored with follow up pelvic examination and ultrasound. Some functional cysts can regress rapidly with intake of combined contraceptive pills [2].

The incidence of ovarian cysts detected in asymptomatic female has increased with the use of ultrasonography (US) and other imaging methods. Among healthy women, $6 \%$ are found to have adnexal masses, $90 \%$ of which are cystic lesions mostly simple cysts and many of these cysts are managed with laparoscopy or laparotomy and it is found that most of these cysts are functional cyst [3].

The cyst wall is the source for fluid production and the subsequent persistence of the cyst [4]. Simple ovarian cysts may undergo many complications like torsion, hemorrhage or rupture if they are larger than $5 \mathrm{~cm}$ in diameter. Removal is advised to avoid these complications. Ultrasound guided needle aspiration substitute surgery or laparoscopy [5].

Surgery may represent overtreatment in these patients, and the cost and risks may outweigh the benefits [4]. Ultrasound-guided aspiration of ovarian cysts with cytological evaluation of the aspirated fluid has been suggested by many investigators with contradictory results about the cure rate with range from $30 \%$ to $80 \%$ [5].

Ultrasound-guided aspiration of an ovarian cyst has been proven to be a good alternative to surgery for carefully selected cysts with no ultrasonography criteria of malignancy. Also it helps patients to avoid risks of laparoscopy and avoid the complications of laparotomy. Ultrasound fine needle aspiration is a quick and safe procedure with a low complication rate [6].

Methotrexate is a folate antagonist and is antimetabolite prototype. It is frequently used in many gynecological and obstetric practices, so when ultrasound guided aspiration of ovarian cyst combined with methotrexate injection into the cyst, it might suppress fluid production by the cyst wall, promote cyst resolution and prevent recurrence [7].

\section{Material and Methods}

\subsection{Study Design}

This randomized controlled study was conducted at Obstetrics and Gynecology Department of Tanta University during the period from April 1, 2016 to October 31, 2016.

\subsection{Patients}

Fifty eligible patients with functional ovarian cyst were randomly allocated into 2 equal groups. Group I: include 25 patients who were subjected to Transvaginal ultrasound guided aspiration only (Control group) and group II: include 25 patients who were subjected to Transvaginal ultrasound guided aspiration and in situ methotrexate injection (Study group).

Randomization was done by simple randomization and alternate allocation. Patients were selected according to inclusion and exclusion criteria.

Inclusion criteria were: (1) Age of patient 20 - 40 years, (2) A simple ovarian cyst with following criteria: (a) Benign architectural feature of cyst at ultrasound: Figure 1. 


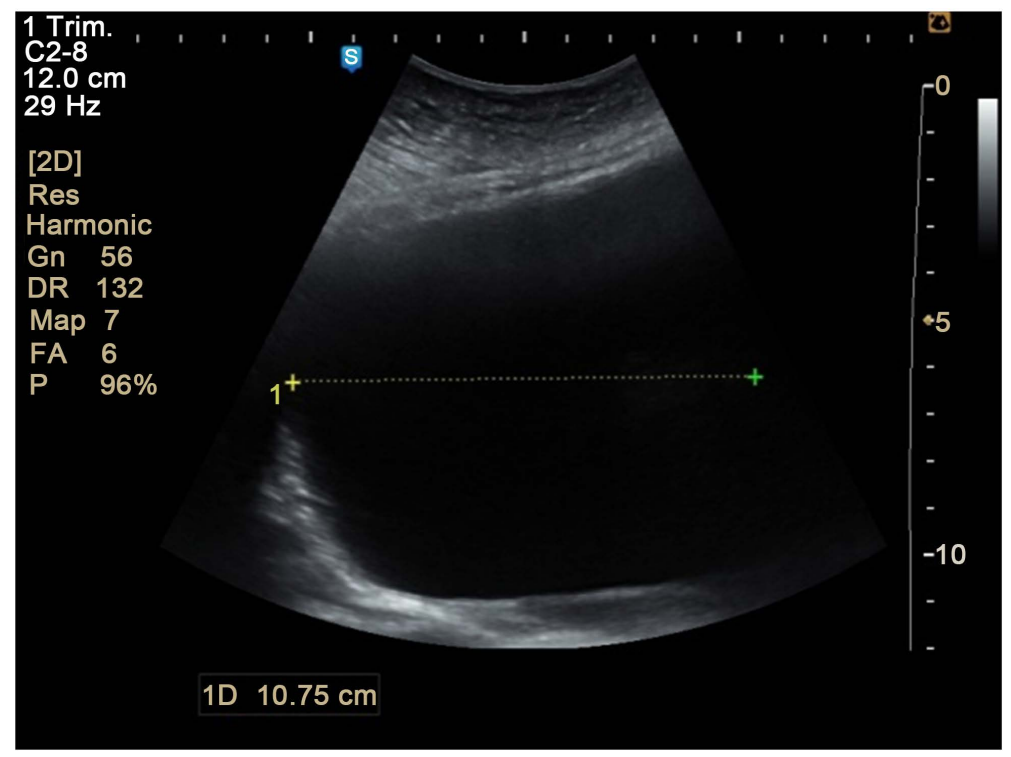

(a)

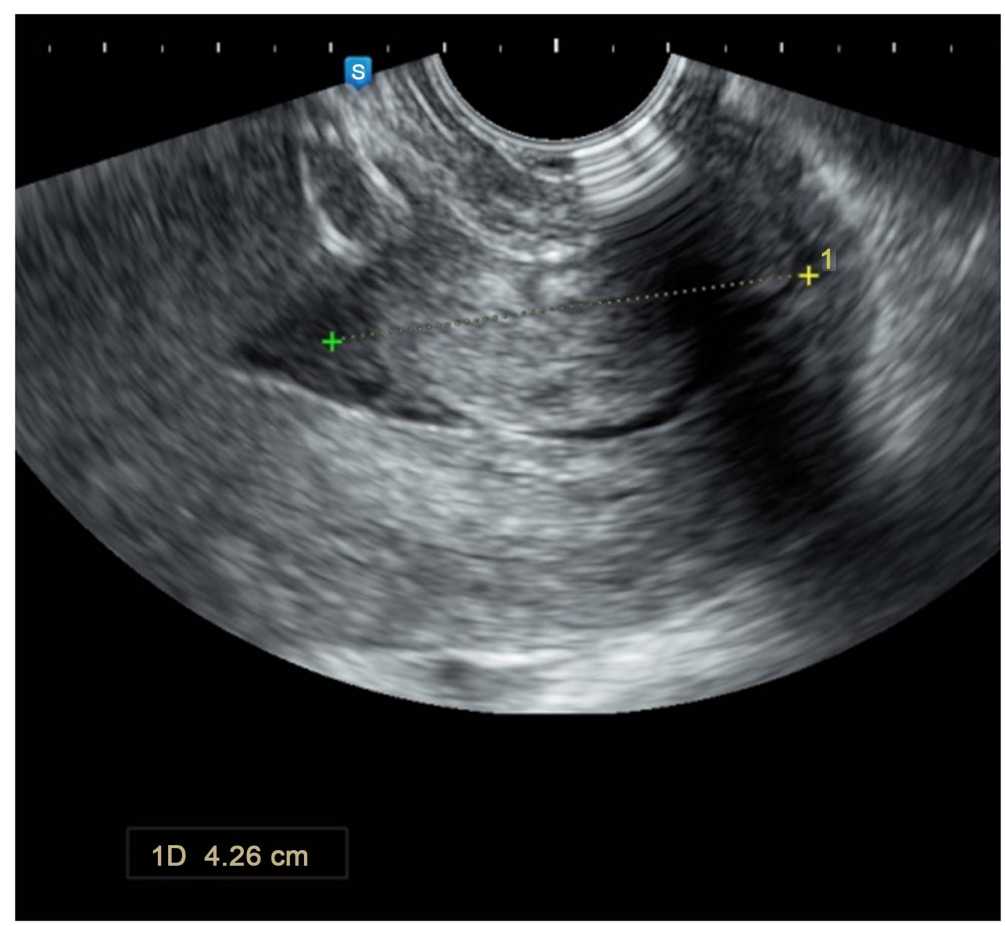

(b)

Figure 1. Simple ovarian cyst. (a) Before aspiration; (b) After aspiration.

- Unilateral cyst.

- Unilocular cyst with no septations or solid areas in the wall.

- No free fluid in Douglas pouch.

- Clear content of the cyst with no turbdity.

(b) Persistent for more than 3 months (c) Cyst diameter more than $5 \mathrm{~cm}$ (3) Failed medical treatment with oral contraceptives (4) No past or family history of ovarian cancer and (5) Normal value of serum caner antigen-125 (CA $125<35$ International unit $/ \mathrm{mL}$ ) before the procedure. Exclusion criteria were: (1) Patients with recurrent cysts 
after previous surgery, (2) Evidence of renal or hepatic disease or hypersensitivity to methotrexate, (3) Age $>40$ ys, (4) previous puncture or excision of the cyst and (5) Virgin and pregnant women.

\subsection{Methods}

All patients were evaluated by detailed history, general and local examination, routine investigations as complete blood picture, renal function tests, liver function tests, and CA-125. Trans-vaginal ultrasound was done to confirm diagnosis and exclude cases with suspicious malignant sonographic criteria.

\subsection{Procedure}

- Preoperative: All patients were advised to use clindamycin vaginal cream for three successful nights before the operation to decrease the vaginal contamination with anaerobic infection as a prophylaxis against introduction of anaerobic infection into the ovary or the peritoneal cavity.

- Intervention: All patients were placed in lithotomy position, and given general anesthesia (IV Propofol Diprivan'). Vaginal cleansing with chlorhexidine was done. The needle guide was attached to the transducer that had been covered with condom. The transducer was then introduced into the vagina; the procedure was done under endovaginal U/S guidance. The needle used 16-gauge, $35 \mathrm{~cm}$ long, attached to transvaginal probe (Samsung Medison. UGEO H60; Korea). This procedure was essentially the same as that used for oocyte pick-up for IVF-ET. In some cases, manual compression of the cyst was performed through anterior abdominal wall to facilitate needle penetration.

Once the needle was in the cyst, it was connected to $50 \mathrm{cc}$ syringe, and the cyst was evacuated completely. Reexamination by U/S to rule out incomplete evacuation or intra-abdominal hemorrhage. A speculum was inserted to enable visualization of vaginal fornix and puncture site. Cyst aspirates were sent for bacteriologic and cytologic examination. These steps are done for all cases.

In group II after complete evacuation of the cyst, irrigation of the cyst was done by injection of methotrexate $50 \mathrm{mg}$. At the procedure, $3 \mathrm{ml}$ of normal saline was added to one ampoule of methotrexate $50 \mathrm{mg}$ and was injected inside cyst cavity under ultrasonic guidance.

- Postoperative: After the procedure the patients were followed up for the next 3 hours for vital signs, abdominal pain, and drug hypersensitivity. Pelvic ultrasonography was done before discharge of patient. Patients were discharged 24 hours after procedure and instructed to contact hospital if fever or abdominal pain or any other symptoms. Combination of oral Azithromycin $500 \mathrm{mg}$ daily and metronidazole 500 mg every 12 hour for 3 days were prescribed for all cases. Ultrasound examination is performed at 1,3, 6 months after the procedure. The cyst was considered resolved if follow up revealed either no cystic lesion or only a follicle-like cyst no more than 25 $\mathrm{mm}$ in diameter.

- Ethical aspects: Risks of intervention including vaginal bleeding, infection, abdominal pain or neurogenic shock were explained to all participants. Written consent 
was taken from all patients before enrollment in the study. The privacy of patients was maintained under all conditions except for authorized persons who work on this research. The study was approved by ethical committee of Tanta University before the start of study.

- Statistical methods: All data were analyzed by SPSS version 18 . The statistical tests used were Range, mean and standard deviation, and percentage. $P$ value of 0.05 or less is considered significant.

\section{Results}

The study was conducted on fifty females with the mentioned inclusion criteria who were allocated into two groups, group I managed by transvaginal ultrasound aspiration of the cyst only, and group II managed by transvainal ultrasound aspiarion and methotrxate injection into aspirated cyst. Demographic data of included patients are shown in Table 1.

There is non-significant difference between both group of patients regarding the age $(P$ value $=0.125)$, gravidity $(P$ value $=0.468)$, Parity $(P$ value $=0.555)$, BMI $(P$ value $=$ $0.999)$, and CA-125 levels $(P$ value $=0.975)$. Menstrual irregularities were the most common presentation in both groups (12 (48\%), 13 (52\%) respectively) followed by infertility and abdominal pain.

Table 1. Distribution of the patients according to the age.

\begin{tabular}{|c|c|c|c|c|}
\hline Parameter & $\begin{array}{c}\text { Group I } \\
\text { Control group } \\
(\mathrm{n}=25)\end{array}$ & $\begin{array}{l}\text { Group II } \\
\text { Study group } \\
(\mathrm{n}=25)\end{array}$ & $\mathrm{X}^{2}$ & $P$ value \\
\hline \multicolumn{5}{|l|}{ Age } \\
\hline Range & $20-40$ & $20-39$ & \multirow{2}{*}{2.444} & \multirow{2}{*}{0.125} \\
\hline Mean \pm SD & $28.80 \pm 5.62$ & $26.52 \pm 4.65$ & & \\
\hline \multicolumn{5}{|l|}{ Gravidity } \\
\hline Range & $1-5$ & $1-5$ & \multirow[t]{2}{*}{0.535} & \multirow[t]{2}{*}{0.468} \\
\hline Mean \pm SD & $2.72 \pm 0.94$ & $2.92 \pm 0.99$ & & \\
\hline \multicolumn{5}{|l|}{ Parity } \\
\hline Range & $0-5$ & $1-4$ & \multirow[t]{2}{*}{0.354} & \multirow[t]{2}{*}{0.555} \\
\hline Mean \pm SD & $1.84 \pm 1.07$ & $2.0 \pm 0.82$ & & \\
\hline \multicolumn{5}{|l|}{ BMI } \\
\hline Range & $22-28$ & $22-29$ & \multirow{2}{*}{3.8} & \multirow{2}{*}{0.999} \\
\hline Mean \pm SD & $24.28 \pm 1.786$ & $25.6 \pm 2.014$ & & \\
\hline \multicolumn{5}{|l|}{ CA 125} \\
\hline Range & $5-26$ & $8-28$ & \multirow{2}{*}{12.414} & \multirow{2}{*}{0.975} \\
\hline Mean $\pm S D$ & $15.4 \pm 6.069$ & $17.88 \pm 5.805$ & & \\
\hline \multicolumn{5}{|l|}{ Presentation } \\
\hline Abdominal pain & $5(20 \%)$ & $4(16 \%)$ & \multirow{4}{*}{7.402} & \multirow{4}{*}{0.683} \\
\hline Abdominal swelling & $1(4 \%)$ & $2(8 \%)$ & & \\
\hline Infertility & $7(28 \%)$ & $6(24 \%)$ & & \\
\hline Menstrual irregularities & $12(48 \%)$ & $13(52 \%)$ & & \\
\hline
\end{tabular}


The size of ovarian cysts in both groups was non-significant $(P$-value $=0.569)$. The operative time was nearly the same $(16.04 \pm 2.507$ versus $16.28 \pm 3.78)$ in control and study groups respectively ( $P$-value $=0.999)$. The volume of fluid aspirated in both groups was $32.76 \pm 9.527 \mathrm{ml}$ in group I and $34.8 \pm 12.291 \mathrm{ml}$ in group II with nonsignificant difference $(P$-value $=0.59)$. Operative complications was 2 cases in group I (one case of cyst rupture and one case of bleeding from needle puncture resolved by vaginal packing) and 3 cases in group II (one case of puncture site bleeding and 2 cases with cyst rupture). All cases showed malignancy-free aspirate. Operative details were shown in Table 2.

The cyst recurrence after 6 month follow up occurred in 4 patients out of 25 women with percentage $16.0 \%$ in group patient I with aspiration only, and $0.0 \%$ in group patient II after aspiration and methotrexate injection in 25 patients with $P$-value 0.037 . There was a significant difference between two groups (Table 3 ).

Only 7 females out of 25 had a desire for future pregnancy in group I, four of them got pregnant $57.1 \%$ within six months, while six female out of 25 in group II had a

Table 2. Operative details in studied cases.

\begin{tabular}{|c|c|c|c|c|}
\hline & $\begin{array}{c}\text { Group I } \\
\text { Control group } \\
(n=25)\end{array}$ & $\begin{array}{l}\text { Group II } \\
\text { Study group } \\
(n=25)\end{array}$ & $\mathrm{X}^{2}$ & $P$ value \\
\hline \multicolumn{5}{|l|}{ Cyst size } \\
\hline $5-8 \mathrm{~cm}$ & $20(80.0 \%)$ & $20(80.0 \%)$ & & \\
\hline$>8 \mathrm{~cm}$ & $5(20.0 \%)$ & $5(20.0 \%)$ & 0.325 & 0.569 \\
\hline Operative time (minutes) & $16.04 \pm 2.507$ & $16.28 \pm 3.78$ & 6.287 & 0.999 \\
\hline Volume of aspirate $(\mathrm{ml})$ & $32.76 \pm 9.527$ & $34.8 \pm 12.291$ & 21.818 & 0.59 \\
\hline Operative complications & 2 & 3 & 0.53 & 1.00 \\
\hline $\begin{array}{l}\text { Cytology and microbiology } \\
\text { of aspirate }\end{array}$ & $\begin{array}{l}\text { Acellular or } \\
\text { benign cells }\end{array}$ & $\begin{array}{l}\text { Acellular or } \\
\text { benign cells }\end{array}$ & & \\
\hline
\end{tabular}

Table 3. Treatment outcome in studied groups.

\begin{tabular}{|c|c|c|c|c|}
\hline & $\begin{array}{c}\text { Group I } \\
\text { Control group } \\
(n=25)\end{array}$ & $\begin{array}{l}\text { Group II } \\
\text { Study group } \\
(\mathrm{n}=25)\end{array}$ & $\mathrm{X}^{2}$ & $P$ value \\
\hline \multicolumn{5}{|l|}{ Recurrence } \\
\hline Yes & $4(16.0 \%)$ & $0(0.0 \%)$ & 4.348 & $0.037^{\star}$ \\
\hline No & $21(84.0 \%)$ & $25(100.0 \%)$ & 5.430 & 0.062 \\
\hline Pregnancy rate in infertility cases & $4 / 7(57.1 \%)$ & $6 / 6(100.0 \%$ & 3.342 & 0.067 \\
\hline \multicolumn{5}{|l|}{ Complications } \\
\hline Dull aching pain & $7 / 25(28 \%)$ & $6 / 25(24 \%)$ & 0.103 & 0.747 \\
\hline Cyst rupture & $1 / 25(4 \%)$ & $2 / 25(8 \%)$ & 0.352 & 0.552 \\
\hline Dizziness & $3 / 25(12 \%)$ & $1 / 25(4 \%)$ & 1.093 & 0.297 \\
\hline Nausea/vomiting & $3 / 25(12 \%)$ & $1 / 25(4 \%)$ & 1.093 & 0.297 \\
\hline Methotrexate leakage & NA & $2 / 25(8 \%)$ & NA & NA \\
\hline Hypersensitivity to Methotrexate & NA & $0 / 25(0 \%)$ & NA & NA \\
\hline
\end{tabular}


desire for future pregnancy and all of them got pregnant $100 \%$ within six months. Statistical analysis shows insignificant difference between two groups (Table 3). The complications of the procedures were demonstrated in Table 3, where complications were mild and not significant between both groups.

\section{Discussion}

Laparoscopic cystectomy is most frequently chosen for treatment of ovarian cyst. Operative laparoscopy is expensive with $13.3 \%$ complication with $0.6 \%$ being major. These are small bowel, ureter, inferior epigastric vessel injuries and incisional hernias. Ovarian cystectomy is associated with high recurrence rate and loss of primordial follicles with the possible risk of affecting residual ovarian function [8] [9].

The current study evaluated and compared the use of methotrexate injection versus the use of transvaginal ultrasound aspiration only as a method of management in $\mathbf{5 0}$ patients with persistent simple ovarian cysts.

Combined use of serum cancer antigen 125 (CA-125) and trans-vaginal ultrasound for assessment of ovarian cyst nature increases the accuracy with a sensitivity of $94.4 \%$ and specificity of $100 \%$ while positive predictive value was $100 \%$ and negative predicate value $98.3 \%[10]$.

Lacey et al. (2006) reported that the use of cancer antigen 125 in combination with ultrasound examination among women with ovarian masses gave accuracy of $100 \%$ (sensitivity of $100 \%$, specificity of $95.2 \%$, positive predictive value of $91.3 \%$ and negative predictive value of 100\%) [11].

In the current study, demographic data, and presentation were matched in both groups (Table 1). Cyst size, operative time, volume aspirated, and cytology results were nearly similar in both groups (Table 2 ).

Methotrexate is an antimetabolite of the folic acid analog type. Methotrexate is the treatment of choice for ectopic pregnancy because of its low toxicity and known high catalytic effect. The risk of affecting the residual ovarian function with this procedure is low because methotrexate injection is intra-cystic and diffusion in the rest of ovary is limited [7]. The use of in situ methotrexate for ectopicpregnancy has never shown ovarian damage [12] [13].

In the current study the methotrexate dose was chosen arbitrarily. It is not known whether the dose should be adjusted according to cyst size. Methotrexate dose used in the present study was less than the dose given in intramuscular injections $(1 \mathrm{mg} / \mathrm{kg})$ or locally injected in the treatment of ectopic pregnancies. Higher dose of methotrexate used in recurrent ovarian cysts may increase the success rate; however it may be associated with increased risk of side effects [13].

In the current study it was found that methotrexate injection had a good significant effect on management of persistent simple ovarian cyst with no recurrence over 6 months as compared with transvaginal ultrasound aspiration alone with ( $P$ value 0.037$)$ (Table 3). It was also found that methotrexate injection had no drawbacks over patients fertility, with non-significant difference as compared with transvaginal ultrasound aspiration alone with ( $P$ value 0.067$)$, but unfortunately only small sample of patients had a desire of future pregnancy (Table 3 ). Also there was non-significant difference be- 
tween methotrexate injection and transvaginal ultrasound aspiration alone as regard complications (Table 3).

After cytological examination of the aspirated fluid, all proven to be benign or acellualr in both group of patients (Table 3).

In the current study complete resolution of ovarian cysts were observed in 46 patients out of 50 women (92.0\%). Mesogitis et al., (2005) reported disappearance of the simple ovarian cysts after in situ methotrexate injection was achieved in 124 of 148 patients (83.8\%) [14].

Many studies compared cyst aspiration alone and aspiration with injection of ehanol [4], tetracycline [15] [16], and SC injection of GnRH antagonists [17] with comparable results to methotrexate in-situ injection [18] [19].

In the current study cyst relapse was observed in 4 out of $50(8.0 \%)$ patients. The reported recurrence rates after sonographically guided aspiration of symptomatic simple ovarian cysts range from 11\% among 18 patients in Duke et al., (2006) [20] to 35.2\% among in the study of Nikolaou et al., (2014) [3].

In the current study cyst relapse was most frequent with cysts $>8 \mathrm{~cm}$ compared to cysts $<8 \mathrm{~cm}$ (72.0\% versus 8.0\%). Mesogitis et al. (2005) [14] reported that the size of the cyst is an independent factor for cyst relapse. In Mesogitis study, complete resolution was observed in 102 of 122 patients (83.6\%) with a simple cyst (serouscyst adenoma in 10 patients, corpus luteum cyst in 5 patients, par ovarian cyst in 2 patients, and follicle cyst in one patient). Cyst diameters were ranged from 3 to $10.5 \mathrm{~cm}$.

The rates of persistence or recurrence after cyst aspiration alone reported in the literature range from $28.6 \%$ to $72.7 \%$ (48 of 66) Marta Castellarnauet et al. (2016) [4]. In the current study, (26.7\%) of patients had dull aching lower abdominal pain before the procedure. Most of them (75\%) reported complete resolution of the symptoms, while the other (25\%) reported persistent (though milder) pain. These results are similar to Mesogitis results.

The development of post aspiration pelvic adhesion, as result of dissemination of the altered blood out of the cyst after aspiration is very difficult to predict. It cannot be judged if the adhesion resulted from the procedure or de novo, so patients in the present study with ovarian cyst were informed about the potential for adhesive disease following trans-vaginal aspiration. The present study clearly indicates that in-situ methotrexate injection has many advantages including short hospital stay, excellent patient tolerance, less invasive than laparoscopic aspiration, less morbidity. In-situ methotrexate injection is a cost effective alternative to the currently used methods for managing cystic ovarian mass particularly for high surgical risk patients.

\section{Limitations of the Study}

The study limitations were refusal of many patients to participate, rupture of some cysts upon puncture by aspiration needle and loss of some patients in regular follow up intervals.

\section{Conclusion}

Trans-vaginal ultrasound guided aspiration \& in situ methotrexate injection is simple, 
non-invasive, safe and effective in the treatment of selected cases of simple ovarian cyst without evidence of malignancy. It may provide an alternative treatment to laparoscopic cystectomy and open surgery in selected patients.

\section{Conflict of Interest}

All authors had no conflict of interest.

\section{References}

[1] Farahani, L. and Datta, S. (2016) Benign Ovarian Cysts. Obstetrics, Gynaecology and Reproductive Medicine, 26, 271-275. https://doi.org/10.1016/j.ogrm.2016.06.003

[2] ACOG Practice Bulletin No. 110 (2010) Noncontraceptive Uses of Hormonal Contraceptives. Obstetrics \& Gynecology, 115, 206-218. https://doi.org/10.1097/AOG.0b013e3181cb50b5

[3] Nikolaou, M., Adonakis, G., Zyli, P., Androutsopoulos, G., Saltamavros, A., Psachoulia, C., et al. (2014) Transvaginal Ultrasound-Guided Aspiration of Benign Ovarian Cysts. Journal of Obstetrics and Gynaecology, 34, 332-335. https://doi.org/10.3109/01443615.2013.874406

[4] Castellarnau, M., García-Tejedor, A., Carreras, R., Cayuela, E. and Ponce, J. (2016) Ultrasound-Guided Aspiration with and without Ethanol Sclerotherapy in the Management of Simple Adnexal Cysts: A Single-Center Experience. Journal of Minimally Invasive Gynecology, 23, 242-251. https://doi.org/10.1016/j.jmig.2015.10.006

[5] Koutlaki, N., Nikas, I., Dimitraki, M., Grapsas, X., Psillaki, A., Mandratzi, J., Liberis, A. and Liberis, V. (2011) Transvaginal Aspiration of Ovarian Cysts: Our Experience over 121 Cases. Minimally Invasive Therapy \& Allied Technologies, 20, 155-159. https://doi.org/10.3109/13645706.2010.532220

[6] Momtaz, M., Ebrashy, A., Aboulghar, M.M., AlKateb, A. and AlSheikha, A.Z. (2008) Transvaginal Ultrasound Guided Needle Aspiration in the Management of Patients with Simple Ovariancysts. Ultrasound in Obstetrics \& Gynecology, 32, 296. https://doi.org/10.1002/uog.5571

[7] Gupta, P. and Huria, A. (2016) Management of Ovarian Cysts with Percutaneous Aspiration and Methotrexate Injection. Nigerian Medical Journal, 57, 19-23.

https://doi.org/10.4103/0300-1652.180566

[8] Taniguchi, F., Sakamoto, Y., Yabuta, Y., Azuma, Y., Hirakawa, E., Nagira, K., Uegaki, T., Deura, I., Hata, K. and Harada, T. (2016) Analysis of Pregnancy Outcome and Decline of Anti-Müllerian Hormone after Laparoscopic Cystectomy for Ovarian Endometriomas. Journal of Obstetrics and Gynaecology Research, 42, 1534-1540. https://doi.org/10.1111/jog.13081

[9] Goh, S.M., Yam, J., Loh, S.F. and Wong, A. (2007) Minimal Access Approach to the Management of Large Ovarian Cysts. Surgical Endoscopy, 21, 80-83. https://doi.org/10.1007/s00464-005-0596-5

[10] Kupesic, S., Kurjak, A., Anic, T., et al. (2007) Three-Dimensional Ultrasound and Power Doppler Improve the Diagnosis of Ovarian Lesions. Gynecologic Oncology, 6, 28-32.

[11] Lacey Jr., J.V., Greene, M.H., Buys, S.S., et al. (2006) Ovarian Cancer Screening in Women with a Family History of Breast or Ovarian Cancer. Obstetrics \& Gynecology, 108, 11761184. https://doi.org/10.1097/01.AOG.0000239105.39149.d8

[12] Shawki, H., Elmorsi, M., Samir, A. and Eissa, M. (2011) In Situ Methotrexate Injection after Transvaginal Ultrasound-Guided Aspiration of Ovarian Endometriomas: A Randomized Controlled Trial. Middle East Fertility Society Journal, 16, 224-231.

https://doi.org/10.1016/j.mefs.2011.02.002 
[13] Mesogitis, S., Antsaklis, A., Daskalakis, G., Papantoniou, N. and Michalas, S. (2000) Combined Ultrasonographically Guided Drainage and Methotrexate Administration for Treatment of Endometriotic Cysts. Lancet, 355, 1160. https://doi.org/10.1016/S0140-6736(00)02071-7

[14] Mesogitis, S., Daskalakis, G., Pilalis, A., Papantoniou, N., Thomakos, N., Dessipris, N., et al. (2005) Management of Ovarian Cysts with Aspiration and Methotrexate Injection. Radiology, 235, 668-673. https://doi.org/10.1148/radiol.2352031442

[15] Kars, B., Buyukbayrak, E.E., Karsidag, A.Y., Pirimoglu, M., Unal, O. and Turan, C. (2012) Comparison of Success Rates of "Transvaginal Aspiration and Tetracycline Sclerotherapy" versus "Only Aspiration” in the Management of Non-Neoplastic Ovarian Cysts. Journal of Obstetrics and Gynaecology Research, 38, 65-69. https://doi.org/10.1111/j.1447-0756.2011.01627.x

[16] Thummalakunta, P.L. and Panditi, S. (2012) Comparison of Success Rates of "Transvaginal Aspiration and Tetracycline Sclerotherapy" versus "Only Aspiration" in the Management of Non-Neoplastic Ovarian Cysts. Journal of Obstetrics and Gynaecology Research, 38, 1342. https://doi.org/10.1111/j.1447-0756.2012.01971.x

[17] Pereira, N., Amrane, S., Hobeika, E., Lekovich, J.P., Chung, P.H. and Rosenwaks, Z. (2016) Cyst Aspiration or GnRH Antagonist Administration for Ovarian Cysts Detected at the Start of Fresh in Vitro Fertilization Cycles. Gynecological Endocrinology, 32, 562-565. https://doi.org/10.3109/09513590.2016.1139565

[18] Sanad, Z.F., Saleh, S.A. and Mostafa, A. (2015) Different Modalities in the Management of Functional Ovarian Cysts. Menoufia Medical Journal, 28, 960-964. https://doi.org/10.4103/1110-2098.173686

[19] Wang, L.L., Dong, X.Q., Shao, X.H. and Wang, S.M. (2011) Ultrasound-Guided Interventional Therapy for Recurrent Ovarian Chocolate Cysts. Ultrasound in Medicine \& Biology, 37, 1596-1602. https://doi.org/10.1016/j.ultrasmedbio.2011.07.004

[20] Duke, D., Colville, J., Keeling, A., Broe, D., Fotheringham, T. and Lee, M.J. (2006) Transvaginal Aspiration of Ovarian Cysts: Long-Term Follow-Up. CardioVascular and Interventional Radiology, 29, 401-405. https://doi.org/10.1007/s00270-005-0167-0

\section{Submit or recommend next manuscript to SCIRP and we will provide best service for you:}

Accepting pre-submission inquiries through Email, Facebook, LinkedIn, Twitter, etc.

A wide selection of journals (inclusive of 9 subjects, more than 200 journals)

Providing 24-hour high-quality service

User-friendly online submission system

Fair and swift peer-review system

Efficient typesetting and proofreading procedure

Display of the result of downloads and visits, as well as the number of cited articles

Maximum dissemination of your research work

Submit your manuscript at: http://papersubmission.scirp.org/

Or contactojog@scirp.org 